\title{
Developmental Changes in Calcium Current Pharmacology and Somatostatin Inhibition in Chick Parasympathetic Neurons
}

\author{
Michael G. White, Mark A. Crumling, and Stephen D. Meriney \\ Department of Neuroscience, University of Pittsburgh, Pittsburgh, Pennsylvania 15260
}

\begin{abstract}
Voltage-dependent calcium $\left(\mathrm{Ca}^{2+}\right)$ currents were characterized and modulatory effects of somatostatin were measured in acutely dissociated chick ciliary ganglion neurons at embryonic stages 34,37 , and 40 . This developmental time period coincides with the period of synapse formation between ciliary ganglion neurons and peripheral eye muscles. At all three developmental stages $\mathrm{Ca}^{2+}$ current could be blocked almost completely by combined application of $\omega$-CgTX GVIA and nitrendipine. At young embryonic ages there was significant overlap in sensitivity, with $\sim 75 \%$ of the current sensitive to either blocker applied independently. By stage 40 , there was very little or no overlap in sensitivity, with $\sim 75 \%$ of the current blocked by $\omega$-CgTX GVIA (N-type) and $30 \%$ blocked by nitrendipine (L-type). These data are consistent with earlier findings that the pharmacology of acetylcholine release from ciliary ganglion
\end{abstract}

nerve terminals changes during development from sensitivity to both dihydropyridines and $\omega$-CgTX GVIA to selective sensitivity to $\omega$-CgTX GVIA (Gray et al., 1992). Somatostatin reduced $\mathrm{Ca}^{2+}$ current by $50-60 \%$ at all three developmental stages. At early developmental stages somatostatin receptors coupled predominantly to the current that was sensitive to both $\omega$-CgTX GVIA and nitrendipine. By stage 40 , somatostatin primarily inhibited classically defined $\mathrm{N}$-type current (selectively sensitive to $\omega$-CgTX GVIA). Thus, somatostatin receptor coupling to $\mathrm{Ca}^{2+}$ channels persisted throughout development as $\mathrm{Ca}^{2+}$ current pharmacology changed.

Key words: calcium channel; somatostatin modulation; development; chick ciliary ganglion; FPL 64176; $\omega$-CgTX GVIA; dihydropyridines
Using pharmacologic manipulations of acetylcholine (ACh) release, previous investigators have concluded that $\mathrm{N}$-type $\mathrm{Ca}^{2+}$ channels regulate transmitter release at the mature parasympathetic neuromuscular junction formed between chick ciliary ganglion neurons and intrinsic eye muscles (Gray et al., 1992). During the development of ciliary ganglion innervation of intrinsic eye muscles, Gray et al. (1992) have identified a switch in the pharmacology of calcium-dependent $\mathrm{ACh}$ release such that, at embryonic ages that correspond with synaptic maturation (embryonic stages 37-39), both $\mathrm{N}$ - and L-type channel blockers influence ACh release. These observations suggest that the types of calcium channels that are expressed or targeted to the nerve terminal change during development. Comparable studies in the hippocampus have revealed a developmental shift in the pharmacologic sensitivities of transmitter release to selective blockers of $\mathrm{N}$ - and Q-type calcium channels (Scholz and Miller, 1995). Taken together, these investigations suggest that, at least in some preparations, the types of calcium channels coupled to transmitter release change during development. Changes in the expression patterns of ion channels are known to be an important feature of neuronal development (O'Dowd et al., 1988; Desarmenien et al., 1993; Spitzer, 1994), and because of the integral role of voltagedependent $\mathrm{Ca}^{2+}$ channels in neurotransmitter release, the types

Received March 13, 1997; revised May 27, 1997; accepted May 30, 1997.

This work was supported by the University of Pittsburgh Small Grants Program, a Winters Foundation award, and National Institutes of Health Grant NS 32345. We thank Guillermo Pilar, D. Bruce Gray, James Simples, Robert Poage, Debra Artim, and John Pattillo for many helpful discussions and critical evaluation of this manuscript and Melanie Kaszer for preparing cultured cells.

Correspondence should be addressed to Dr. Stephen D. Meriney, Department of Neuroscience, University of Pittsburgh, 446 Crawford Hall, Pittsburgh, PA 15260.

M.A. Crumling's present address: David Mahoney Institute of Neurological Sciences, University of Pennsylvania, 215 Stemmler Hall, Philadelphia, PA 19104-6074 Copyright (C) 1997 Society for Neuroscience $0270-6474 / 97 / 176302-12 \$ 05.00 / 0$ of calcium channels expressed are critical. In addition, the N-type calcium channels present at these and other synapses are often the target of G-protein-coupled receptors that have potent presynaptic neuromodulatory actions (Hille, 1994). As such, the capacity for neuromodulation may undergo developmental changes that are associated with changes in the expression of calcium channels. Thus, developmental changes in calcium channel expression are likely to be important for the control of transmitter release as well as the effects of neuromodulators.

We have studied the developmental changes in calcium current pharmacology and the neuromodulatory effects of somatostatin in chick ciliary ganglion neurons. Somatostatin is endogenous to choroid neurons in the chick ciliary ganglion (Epstein et al., 1988; Coulombe and Nishi, 1991; De Stefano et al., 1993) and is a potent inhibitor of transmitter release at choroid nerve terminals (Gray et al., 1989, 1990). Despite the selective expression of the somatostatin peptide in choroid neurons, somatostatin receptors are expressed on essentially all neurons in the embryonic ciliary ganglion (Meriney et al., 1994). We report a developmental change in the pharmacology of calcium channels expressed at three time points that correspond to the development of synapses with intrinsic eye muscles. Throughout this developmental change in calcium current pharmacology, somatostatin remains an effective modulator of calcium channels.

\section{MATERIALS AND METHODS}

Cell culture. Ciliary ganglia were dissected from White Leghorn chicken eggs [stages 34, 37, or 40, as determined by Hamburger and Hamilton (1951)] in sterile oxygenated Tyrode containing (in $\mathrm{mM}$ ): $134 \mathrm{NaCl}, 3$ $\mathrm{KCl}, 3 \mathrm{CaCl}_{2}, 1 \mathrm{MgCl}_{2}, 12$ glucose, and $20 \mathrm{NaH}_{2} \mathrm{CO}_{3}, \mathrm{pH}$ 7.2. Ganglia were incubated in $0.08 \%$ trypsin in $\mathrm{Ca}^{2+}$ - and $\mathrm{Mg}^{2+}$-free Tyrode for 12 , 15 , or $20 \mathrm{~min}$ at $37^{\circ} \mathrm{C}$ for stages 34,37 , and 40 ganglia, respectively. Trypsin was removed and inhibited by three washes in minimal essential media (MEM) plus $10 \%$ heat-inactivated horse serum. Ganglia were 
dissociated mechanically by gentle trituration. The final suspension of cells was centrifuged at $100 \times g$ for $5 \mathrm{~min}$. The pelleted cells were resuspended in MEM plus $10 \%$ chick embryo extract, plated onto polyL-lysine-coated $35 \mathrm{~mm}$ plastic dishes, and incubated at $37^{\circ} \mathrm{C}$. Cells were used for experiments after $2-6 \mathrm{hr}$ of incubation, at which time there were no neurites elaborated onto the poly-L-lysine substrate.

Perforated patch-clamp recordings. For most recordings, the perforated patch technique was used to gain electrical access to the cell interior while allowing only the exchange of small monovalent ions between the pipette and the cell cytoplasm (Horn and Marty, 1988). To isolate the inward current through $\mathrm{Ca}^{2+}$ channels, we bathed the cells in an external saline of the following composition (in $\mathrm{mM}$ ): $140 \mathrm{NaCl}, 20 \mathrm{TEA}-\mathrm{Cl}, 10$ HEPES, 5 glucose, $5 \mathrm{KCl}, 5 \mathrm{CaCl}_{2}$, and $2 \mathrm{MgCl}_{2}$ plus $2 \mu \mathrm{M}$ tetrodotoxin, $\mathrm{pH}$ 7.3. Pipettes were pulled in a two-step process, coated with SYLGARD (Dow Corning, Midland, MI), and fire-polished (electrode resistances ranged from 0.5 to $2 \mathrm{M} \Omega$ ). The pipette was filled in a two-step manner. The tip was filled by a $5 \mathrm{sec}$ dip in an internal solution of (in $\mathrm{mM}): 75 \mathrm{Cs}_{2} \mathrm{SO}_{4}, 55 \mathrm{CsCl}, 8 \mathrm{MgCl}_{2}$, and 10 HEPES, $\mathrm{pH}$ 7.3. The remainder of the pipette was back-filled with the above solution plus 400 $\mu \mathrm{g} / \mathrm{ml}$ of amphotericin B (Rae et al., 1991). Amphotericin B gradually induced a low-resistance pathway that reached equilibrium within 5-15 min after seal formation (measured by changes in the area and decay time constant of the capacitive transient associated with a $10 \mathrm{mV}$ hyperpolarizing voltage step; see Fig. $1 D$ ), with a series resistance of $13.93 \pm$ $6.34 \mathrm{M} \Omega($ mean $\pm \mathrm{SD} ; n=167)$. At this point, recordings of $\mathrm{Ca}^{2+}$ current were made for up to $1 \mathrm{hr}$ without complications caused by the loss of cytoplasmic components. Except where noted, currents were activated by depolarizing steps from $-80 \mathrm{mV}$ to $+10 \mathrm{mV}$. Currents were activated, acquired, and leak-subtracted with a hyperpolarizing $\mathrm{P} / 4$ protocol by the pClamp (Axon Instruments, Foster City, CA) software package running on a 486 microcomputer in concert with an Axopatch $200 \mathrm{~A}$ patch-clamp amplifier. The currents were four-pole Bessel-filtered at $5 \mathrm{kHz}$ and digitized at $20 \mathrm{kHz}$. With the exception of access resistance measures reported in this section, all values expressed are means $\pm \mathrm{SE}$.

Whole-cell patch-clamp recordings. In those cases in which pharmacologic effects were measured on calcium tail currents, the traditional whole-cell patch-clamp method was used. This was done to increase the reliability of recording tail currents immediately after the cessation of the test pulse (see Fig. 6, inset). Measurements of FPL 64176-elongated tail currents were made $10 \mathrm{msec}$ after the cessation of the test pulse and thus were not influenced by the use of perforated or traditional whole-cell methods. For experiments with whole-cell methods, the same pipette size and bath solution were used, but the pipettes were filled with the following internal solution (in mM): $120 \mathrm{CsCl}, 10 \mathrm{HEPES}, 11$ EGTA, 5 TEA-Cl, $1 \mathrm{CaCl}_{2}$, and $4 \mathrm{MgCl}_{2}$, with 4 ATP-Mg, 0.3 GTP-Na, and 0.1 leupeptin added fresh daily to slow the loss of $\mathrm{Ca}^{2+}$ current caused by cytoplasmic dialysis. After gigaseal formation, access to the cell interior was gained by applying further suction and rupturing the piece of membrane under the patch electrode (access resistance averaged $8.48 \pm$ $5.86 \mathrm{M} \Omega$, mean $\pm \mathrm{SD} ; n=72$ ).

Pharmacologic agents. Stock solutions of nitrendipine [Research Biochemicals International (RBI), Natick, MA] were made fresh daily in DMSO and diluted to a final concentration of 2-20 $\mu \mathrm{M}$ into the bath saline. FPL 64176 (the generous gift of Dr. David Rampe, Marion Merrell Dow, Cincinnati, OH) or Bay K 8644 (RBI) were solubilized in $\mathrm{ETOH}$ at $1 \mathrm{~mm}$ and diluted into bath saline to $1 \mu \mathrm{M}$. DMSO or ETOH vehicles $(0.1 \%)$ were without effect on calcium current. $\omega$-Aga IVA (Alamone Labs, Jerusalem, Israel) was solubilized in aqueous solution with $0.1 \%$ cytochrome $c$ at $20 \mu \mathrm{M}$, stored at $-80^{\circ} \mathrm{C}$ until the day of use, and diluted into bath saline to $200 \mathrm{~nm}$ with $0.1 \%$ cytochrome $c$. $\omega$-CgTX GVIA (Sigma, St. Louis, MO) was diluted into bath saline to a final concentration of 1-2 $\mu \mathrm{M}$. Somatostatin (Sigma) was diluted into bath saline to a final concentration of $100 \mathrm{~nm}$. All other reagents were obtained from Sigma and dissolved in saline. All pharmacologic agents were applied through a pipette (20-30 $\mu \mathrm{m}$ tip diameter) directly to the cell under study.

\section{RESULTS}

\section{Calcium current expressed in developing ciliary ganglion neurons}

Calcium current was studied via perforated patch-clamp techniques in acutely isolated chick ciliary ganglion neurons at three developmental stages $(34,37$, and 40). As expected from previous reports (Dourado and Dryer, 1992), voltage-activated $\mathrm{Ca}^{2+}$ cur- rents increased in both amplitude and density from developmental stages 34 to 40 . At stage 34, peak current amplitude averaged $217.7 \pm 15.6 \mathrm{pA}$ (mean $\pm \mathrm{SEM} ; n=74$ ), and current density averaged $42.8 \pm 2.1 \mathrm{pA} / \mathrm{pF}$. At stage 37 , peak current amplitude increased to $430.5 \pm 20.1(n=68)$, while current density remained very similar $(45.4 \pm 1.6)$, suggesting that calcium channel numbers increased in parallel with cell size between these two developmental stages (whole-cell capacitance increased from $5.1 \pm 0.3 \mathrm{pF}$ at stage 34 to $9.5 \pm 0.3 \mathrm{pF}$ at stage 37$)$. By stage 40 , peak current amplitude increased to $704.8 \pm 38.4 \mathrm{pA}(n=97)$, and current density increased to $64.3 \pm 2.2 \mathrm{pA} / \mathrm{pF}$ as cell size increased further (whole-cell capacitance averaged $11.1 \pm 0.4$ $\mathrm{pF}$ ). Thus, during the $6 \mathrm{~d}$ of development in vivo between stages 34 and 40, current amplitude increased slightly more than threefold, whereas current density increased by only $\sim 50 \%$, with the only significant density increase occurring between stages 37 and 40 ( $p<0.05$; one-way ANOVA with Tukey's post hoc test). Current-voltage relationships (Fig. $1 A, B$ ) differed only in the amount of current measured at each developmental stage. When current-voltage relationships for each developmental age were corrected for estimated cell size (peak current divided by cell capacitance; $\mathrm{pA} / \mathrm{pF}$ ), the curves overlapped for stages 34 and 37, with a slight increase in the current density $(\mathrm{pA} / \mathrm{pF})$ observed by stage 40 (Fig. 1C). Thus, despite increases in calcium current amplitude, cell size, and current density by stage 40 , currentvoltage relationships appeared very similar.

To characterize the $\mathrm{Ca}^{2+}$ current further, we performed a pharmacologic dissection of $\mathrm{Ca}^{2+}$ currents at stages 34,37 , and 40 . At all three developmental stages, essentially all of the current could be blocked either by $100 \mu \mathrm{M}$ cadmium (data not shown) or by using a combination of $1 \mu \mathrm{M} \omega$-CgTX GVIA and 2-20 $\mu \mathrm{M}$ nitrendipine (Fig. 2). At stage 34, when applied independently, $\omega$-CgTX GVIA inhibited $73.4 \pm 2.9 \%(n=14)$ of the peak $\mathrm{Ca}^{2+}$ current, whereas nitrendipine blocked $72.9 \pm 2.2 \%(n=14$; Fig. $2 A)$. These data suggest a substantial pharmacologic overlap of $\sim 45 \%$. Sequential applications of nitrendipine, followed by $\omega$-CgTX GVIA plus nitrendipine (Fig. $2 B$ ), or $\omega$-CgTX GVIA, followed by nitrendipine plus $\omega$-CgTX GVIA (Fig. $2 C$ ), revealed differences in the percentage of current blocked by each antagonist, but the combined action of both antagonists inhibited $93.3 \pm 2.2 \%(n=9)$ of peak $\mathrm{Ca}^{2+}$ current. This represents essentially complete block of the $\mathrm{Ca}^{2+}$ current. At stage 37, $\omega$-CgTX GVIA alone inhibited $70.3 \pm 2.5 \%(n=15)$ of the peak $\mathrm{Ca}^{2+}$ current, whereas nitrendipine blocked $51.2 \pm 2.0 \%(n=20$; Fig. $2 D)$. At this stage the data suggest a pharmacologic overlap of $\sim 20 \%$ among $\mathrm{Ca}^{2+}$ channel types sensitive to $\omega$-CgTX GVIA and nitrendipine. Applications of nitrendipine, followed by $\omega$-CgTX GVIA plus nitrendipine (Fig. $2 E$ ), or $\omega$-CgTX GVIA, followed by nitrendipine plus $\omega$-CgTX GVIA (Fig. $2 F$ ), showed similar results to the data presented above for stage 34 , with almost all of the $\mathrm{Ca}^{2+}$ current blocked. At stage 40, $\omega$-CgTX GVIA alone inhibited an average of $75.2 \pm 1.2 \%(n=23)$ of the peak $\mathrm{Ca}^{2+}$ current, whereas nitrendipine alone inhibited $31.9 \pm 2.8 \%(n=30$; Fig. $2 G$; block by 2,10 , or $20 \mu \mathrm{M}$ was identical). These numbers account almost exactly for the total composition of the $\mathrm{Ca}^{2+}$ current, with possibly $\sim 5 \%$ pharmacologic overlap still present. Sequential application of $\omega$-CgTX GVIA and nitrendipine in either order had similar effects, and together inhibited $89.1 \pm 2.7 \%(n=6$; Fig. $2 H, I)$ of peak $\mathrm{Ca}^{2+}$ current. The presence of a small resistant current also suggests that some pharmacologic overlap still may be present at stage 40. The small percentage of uncharacterized current that appears to be resistant to both blockers at all three developmental 


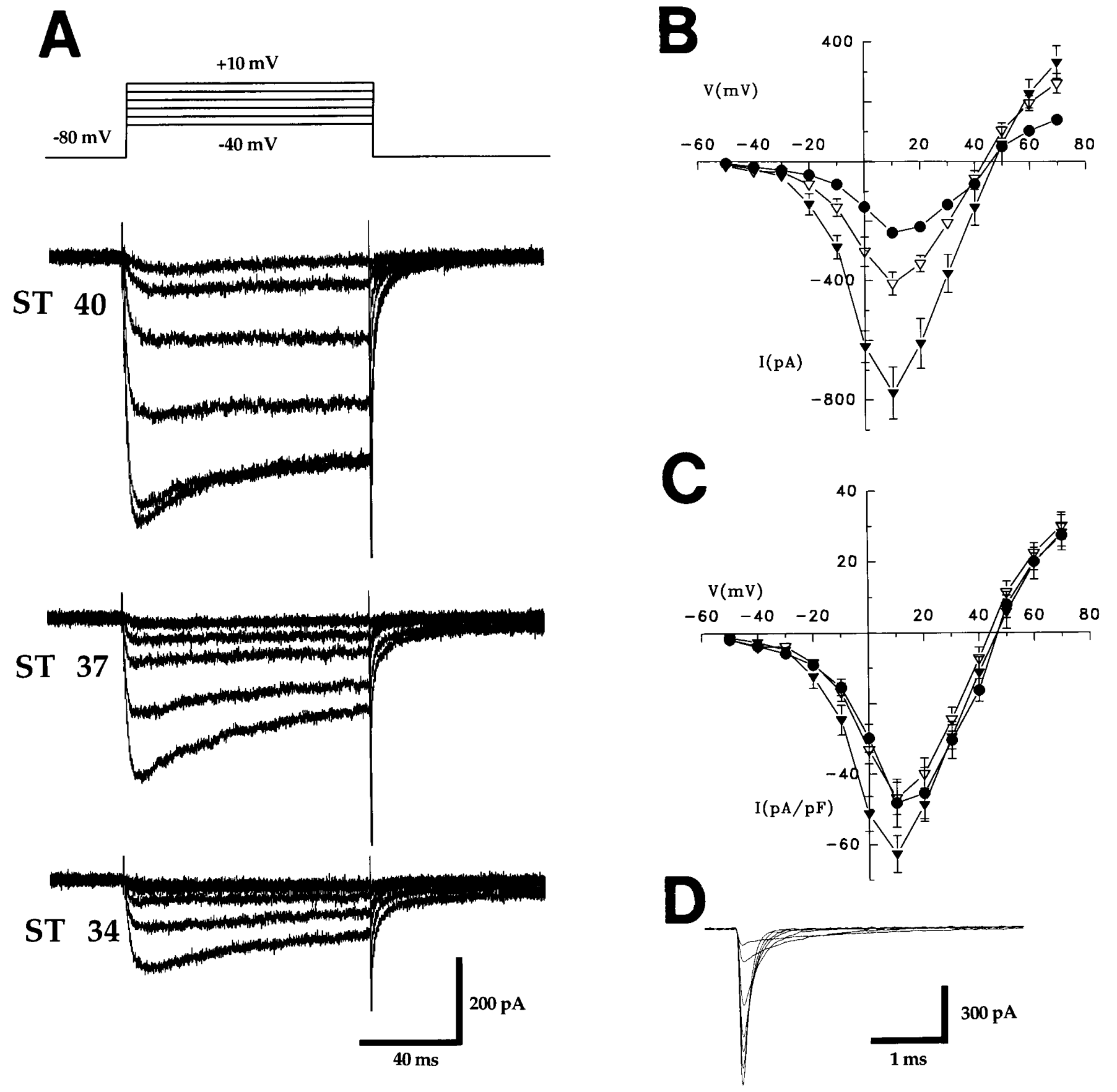

Figure 1. Developmental increase in the magnitude of calcium current recorded via perforated patch-clamp techniques from embryonic chick ciliary ganglion neurons. A, Representative examples of calcium current recorded from three embryonic stages (stage 40, top traces; stage 37, middle traces; stage 34 , bottom traces) in response to voltage steps from -80 to $-40 \mathrm{mV}$ through $10 \mathrm{mV}$. B. Current-voltage relationship of currents recorded at stage 34 ( filled circles), stage 37 (open triangles), and stage 40 ( filled triangles). Values represent the mean \pm SEM of 10 representative cells from each embryonic age. $C$, Current density-voltage relationship for the same data shown in $B . D$, Representative time course of the development of electrical access during the initiation of perforated patch recordings. Overlapping records were taken 5, 30, 60, 90, 120, 150, 180, and 360 sec after seal formation. In this example, at $360 \mathrm{sec}$ the capacitance measured $9.7 \mathrm{pF}$, and the time constant for decay of the capacitive transient measured $0.08 \mathrm{msec}($ access resistance, $9.1 \mathrm{M} \Omega$ ).

stages could be attributed to incomplete block by the antagonists or another minor $\mathrm{Ca}^{2+}$ channel type. Application of $200 \mathrm{nM} \omega$-Aga IVA, a selective blocker of P/Q-type calcium channels, had no significant effect (data not shown). In summary, although $1 \mu \mathrm{M}$ $\omega$-CgTX GVIA blocked 70-75\% of the current at all three developmental stages studied, the magnitude of current sensitive to nitrendipine decreased from $\sim 73 \%$ at stage 34 to only $\sim 30 \%$ at stage 40 . At stage 34 both pharmacologic agents appeared capable of blocking a common subpopulation of $\mathrm{Ca}^{2+}$ channels that represented $\sim 45 \%$ of the total current. At stage 37, this overlap was reduced to only $\sim 20 \%$; by stage 40 , pharmacologic overlap appeared to be $<10 \%$. The pharmacologic sensitivity of calcium currents to $\omega$-CgTX GVIA and dihydropyridine antagonists reported here at stage 40 are similar to that previously reported at this embryonic stage by Yawo and Momiyama (1993) (for review, see Dryer, 1994). 

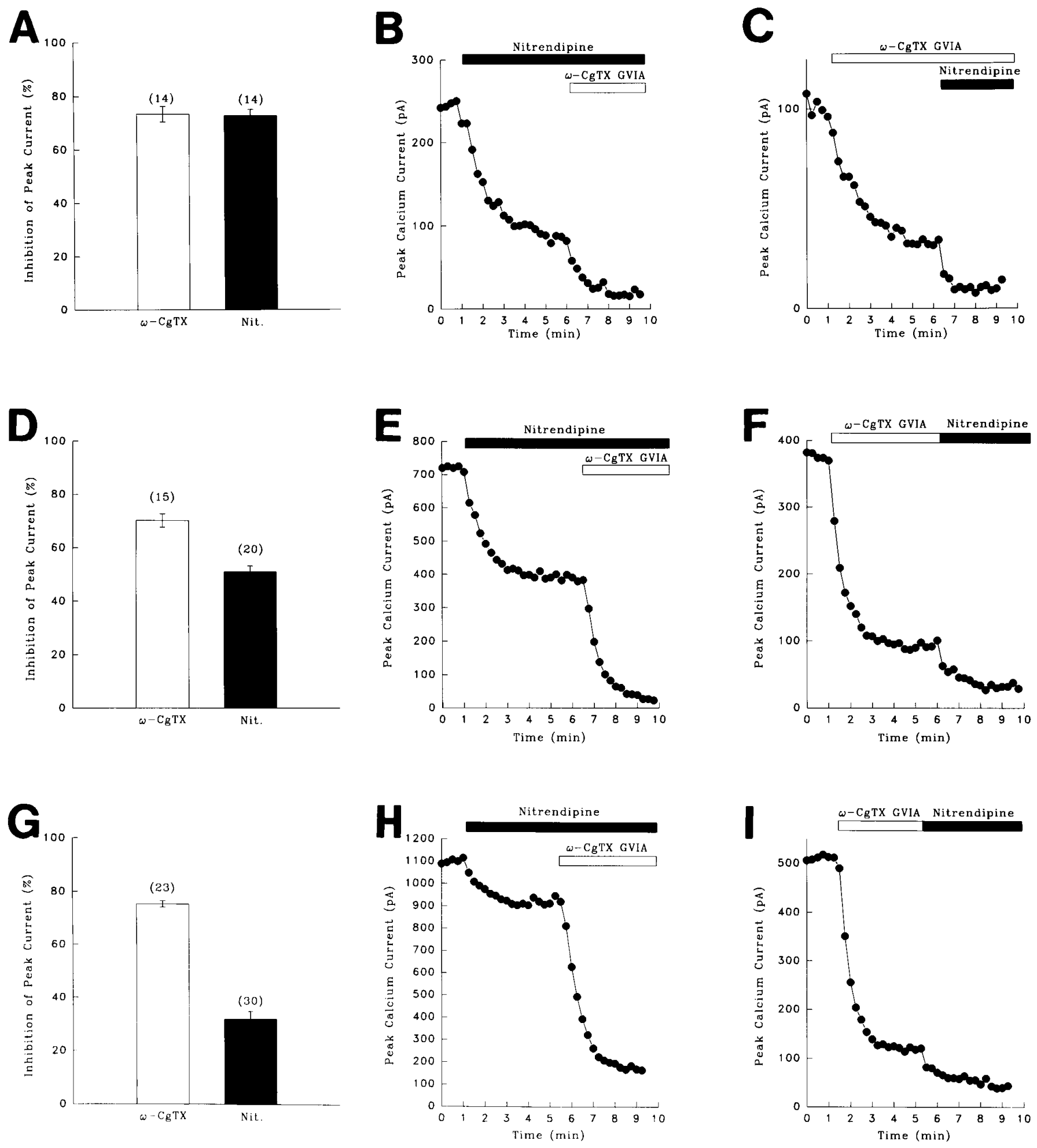

Figure 2. Pharmacologic sensitivity of calcium current recorded via perforated patch-clamp techniques at stages $34(A-C), 37(D-F)$, and $40(G-I)$. At stage 34, nitrendipine (Nit.) or $\omega$-CgTX GVIA $(\omega$-CgTX) blocked a similar percentage of calcium current $(A)$. When they were applied sequentially in either application order $(B, C)$, they blocked almost all of the current with a large amount of overlap in pharmacologic sensitivity. At stage 37, $\omega$-CgTX continued to block $\sim 75 \%$ of the current, but the nitrendipine effect was reduced $(D)$. The apparent overlap in pharmacologic sensitivity at stage 37 was less than at stage 34, as revealed by sequential application of $\omega$-CgTX and nitrendipine $(E, F)$. By stage 40 , although $\omega$-CgTX continued to block $\sim 75 \%$ of the current, the nitrendipine block was reduced to $\sim 30 \%(G)$. Furthermore, sequential application of both blockers in either application order suggested very little overlap in pharmacologic sensitivity $(H, I)$. For the experimental examples represented in plots $F$ and $I$, $\omega$-CgTX was not present during nitrendipine application. Nitrendipine $(20 \mu \mathrm{M})$ and $\omega$-CgTX GVIA $(2 \mu \mathrm{M})$ were used in each representative time course shown. Numbers in parentheses represent the number of cells studied. 
To examine further the apparent sensitivity of a subpopulation of $\mathrm{Ca}^{2+}$ channels to both $\omega$-CgTX GVIA and nitrendipine at stage 34 and stage 37 , we used traditional whole-cell recordings of $\mathrm{Ca}^{2+}$ current to evaluate the effects of $\omega$-CgTX GVIA on elongated L-type tail currents induced by the L-type channel agonist FPL $64176(1 \mu \mathrm{M})$. FPL 64176 is a benzoylpyrrole calcium channel activator (McKechnie et al., 1989; Kunze and Rampe, 1992) that is selective for L-type calcium channels and is more potent than Bay K 8644 (Rampe et al., 1993; Randall and Tsien, 1995). $\omega$-CgTX GVIA $(1 \mu \mathrm{M})$ reversibly blocked (see Fig. $3 E$ ), by $50.6 \pm$ $6.4 \%$ at stage $34(n=13)$ and $20.2 \pm 2.2 \%$ at stage $37(n=13)$, the FPL 64176-elongated L-type tail current (Fig. 3A-E). By stage 40 , only $12.5 \pm 3.5 \%(n=9)$ of the tail current was blocked by $\omega$-CgTX GVIA (Fig. $3 A, F, G$ ). The percentages reported here are strikingly similar to the pharmacologic overlap estimated above, based on blockade of peak current. These data support the conclusion that a significant percentage of the calcium channels expressed at stage 34 and stage 37 is sensitive to two pharmacologic agents that traditionally distinguish $\mathrm{N}$-type from L-type calcium channels.

\section{Somatostatin modulation of calcium current}

The effect of $100 \mathrm{~nm}$ somatostatin on the $\mathrm{Ca}^{2+}$ channel types expressed in ciliary ganglion neurons at different developmental stages also was studied via perforated patch recording techniques. Somatostatin has been shown to be a potent modulator of calcium current in stage 40 ciliary ganglion neurons (Dryer et al., 1991; Meriney et al., 1994). We have extended these observations to modulatory effects at different developmental stages. The effect of somatostatin on peak $\mathrm{Ca}^{2+}$ current at stages 34,37 , and 40 appeared to be relatively constant. At stage $34,58.8 \pm 4.6 \%(n=$ 8; Fig. $4 A$ ) of peak $\mathrm{Ca}^{2+}$ current was blocked. Stage 37 cells showed a $50.5 \pm 1.7 \%(n=8$; Fig. $4 C)$ inhibition by somatostatin, and at stage 40 , somatostatin blocked $51.8 \pm 2.2 \%(n=18$; Fig. $4 E$ ) of the peak $\mathrm{Ca}^{2+}$ current. When it was recorded with the perforated patch technique, somatostatin-mediated modulation at all developmental stages was persistent and reproducible on repeated application (Fig. 4B,D,F; see also Meriney et al., 1994).

The calcium channel blockers $\omega$-CgTX GVIA and nitrendipine were used to determine whether the contribution of $\mathrm{Ca}^{2+}$ channel types to the current inhibited by somatostatin changed with the progressive developmental alterations in calcium current pharmacology described above. At stage 34, pretreatment with $\omega$-CgTX GVIA reduced the somatostatin effect to $4.7 \pm 0.7 \%$ (expressed as a percentage of peak current before pharmacologic manipulation; $n=8$; Fig. $5 A, C$ ), occluding $\sim 90 \%$ of the somatostatin effect at this stage. Similarly, pretreatment with nitrendipine reduced the somatostatin effect to $11.1 \pm 1.2 \%(n=7$; Fig. $5 A, B)$, occluding $\sim 80 \%$ of the somatostatin effect at stage 34 . These data indicate that, at stage 34 , somatostatin inhibits almost exclusively the mixed pharmacologic channel type sensitive to both $\omega$-CgTX GVIA and nitrendipine.

At stage 37, pretreatment with $\omega$-CgTX GVIA reduced the somatostatin effect to $7.6 \pm 1.5 \%(n=15$; Fig. $5 D, F)$, occluding $\sim 85 \%$ of the somatostatin inhibition. Pretreatment with nitrendipine reduced the effect of somatostatin to $29.3 \pm 2.6 \%(n=15$; Fig. $5 D, E$ ), occluding $\sim 45 \%$ of the somatostatin inhibition. Thus, at stage 37 , somatostatin affected the mixed pharmacologic channel type sensitive to both $\omega$-CgTX GVIA and nitrendipine as well as a significant percentage of the current that was sensitive selectively to $\omega$-CgTX GVIA.

At stage 40, pretreatment with $\omega$-CgTX GVIA diminished the somatostatin effect to $7.7 \pm 0.6 \%$ ( $n=19$; Fig. 5G,I), blocking $\sim 85 \%$ of the somatostatin-mediated inhibition. Pretreatment with nitrendipine at stage 40 had only a slight effect, reducing the SOM-mediated $\mathrm{Ca}^{2+}$ current inhibition to $40.0 \pm 1.9 \%(n=20$; Fig. $5 G, H)$, occluding only $\sim 20 \%$ of the control somatostatin effect. Because there seemed to be $<10 \%$ overlap in calcium current pharmacology (see Fig. $2 G$ above), these data indicate a predominant effect of somatostatin at stage 40 on classically defined N-type calcium channels, along with a smaller effect on mixed pharmacologic or L-type $\mathrm{Ca}^{2+}$ channels. In fact, the effect of somatostatin at stage 40 may be restricted to $\mathrm{N}$-type and the small percentage of mixed pharmacologic type that remains at this stage.

To test further the hypothesis that somatostatin targets calcium channels sensitive to L-type calcium channel agents, we performed traditional whole-cell recordings at stages 34,37 , and 40 of FPL 64176-elongated tail currents, and we tested the effects of somatostatin. The only differences between somatostatin effects measured via traditional whole-cell and perforated whole-cell methods are the activation kinetics of the modulated current (slowed in traditional whole-cell, but not in perforated, methods) and the desensitization rate (faster in traditional whole-cell method; see Meriney et al., 1994). Differences in somatostatin effects are limited to these characteristics of the inhibition that are dependent on cytoplasmic second messengers, and there is no difference in the types of calcium channels recorded or the sensitivity of these channels to somatostatin. At all three stages somatostatin had little or no detectable effect on FPL 64176elongated tail currents (Fig. 6), although somatostatin did reduce the fast component of the tail current (see Fig. 6, inset). In some experiments perforated patch techniques were used with identical results (data not shown). Similarly, somatostatin was without effect on tail currents elongated by treatment with $1 \mu \mathrm{M}$ BAY K $8644(3.2 \pm 2.4 \% ; n=5$ at stage 34$)$. The lack of somatostatinmediated modulation of FPL 64176-elongated tail currents would have been expected if the current types present in FPL 64176elongated tail current were distinct from those contributing to the fraction of peak current that was sensitive to somatostatinmediated modulation. However, because nitrendipine occluded somatostatin effects on peak current (see Fig. 5), this suggests that calcium channels sensitive to L-type blockers are affected by somatostatin. Furthermore, somatostatin seemed to target predominantly the peak current characterized by mixed pharmacologic sensitivity at stage 34 (Fig. 5), and $\omega$-CgTX GVIA blocked $\sim 50 \%$ of the FPL 64176-elongated tail current at this early embryonic stage (Fig. 3). These data suggest that the FPL 64176elongated tail current recorded at stage 34 (Fig. 6 $\mathrm{A}$ ) includes a significant percentage of the mixed pharmacologic channel type that has been shown to be sensitive to somatostatin. Thus, it is surprising that somatostatin had no effect on this mixed pharmacologic calcium tail current.

To characterize the effect of somatostatin further, we performed an examination of the somatostatin effect on calcium current activated at different voltages at stage 34 and revealed an apparent biphasic voltage dependence (Fig. 7). There was no apparent effect of somatostatin on calcium current when it was measured at membrane potentials more positive than approximately $+35 \mathrm{mV}$ or more negative than approximately $-15 \mathrm{mV}$. A similar voltage dependence was observed at stages 37 and 40 (data not shown) (see also Meriney et al., 1994). To compare the effects of somatostatin and pharmacologic blockers on current activated by test potentials with relatively hyperpolarized poten- 

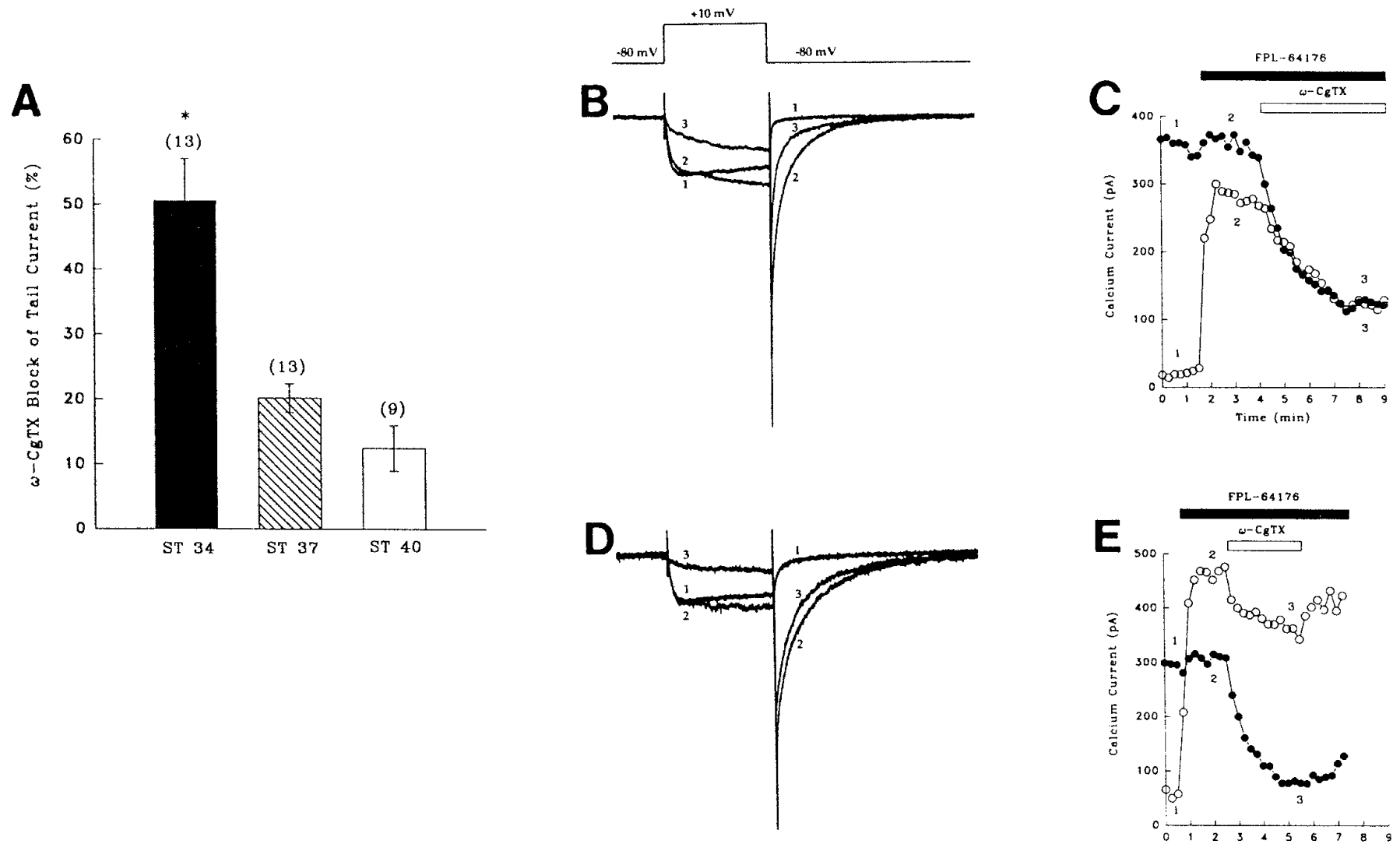

Figure 3. $\omega$-CgTX GVIA blocked FPL 64176-elongated tail currents recorded via traditional whole-cell recording techniques at early embryonic stages. $A$, Plot of the effects of $\omega$-CgTX GVIA $(\omega$-CgTX) on FPL 64176-elongated tail currents measured $10 \mathrm{msec}$ after the cessation of the test pulse at stage 34 (solid bar), stage 37 (hatched bar), and stage 40 (open bar). Numbers in parentheses represent the number of cells studied. The stage 34 effect was significantly different from the other groups $(p<0.005$; one-way ANOVA with Tukey's post hoc test). Shown is a representative example of calcium current recorded at stages $34(B), 37(D)$, and $40(F)$ at the points indicated on the plots $(C, E, F$, respectively) of peak current ( filled circles) and tail current (open circles). In all cases, currents were measured isochronally: peak current was measured at the time when control currents peak; tail current was measured $10 \mathrm{msec}$ after the cessation of the test pulse.
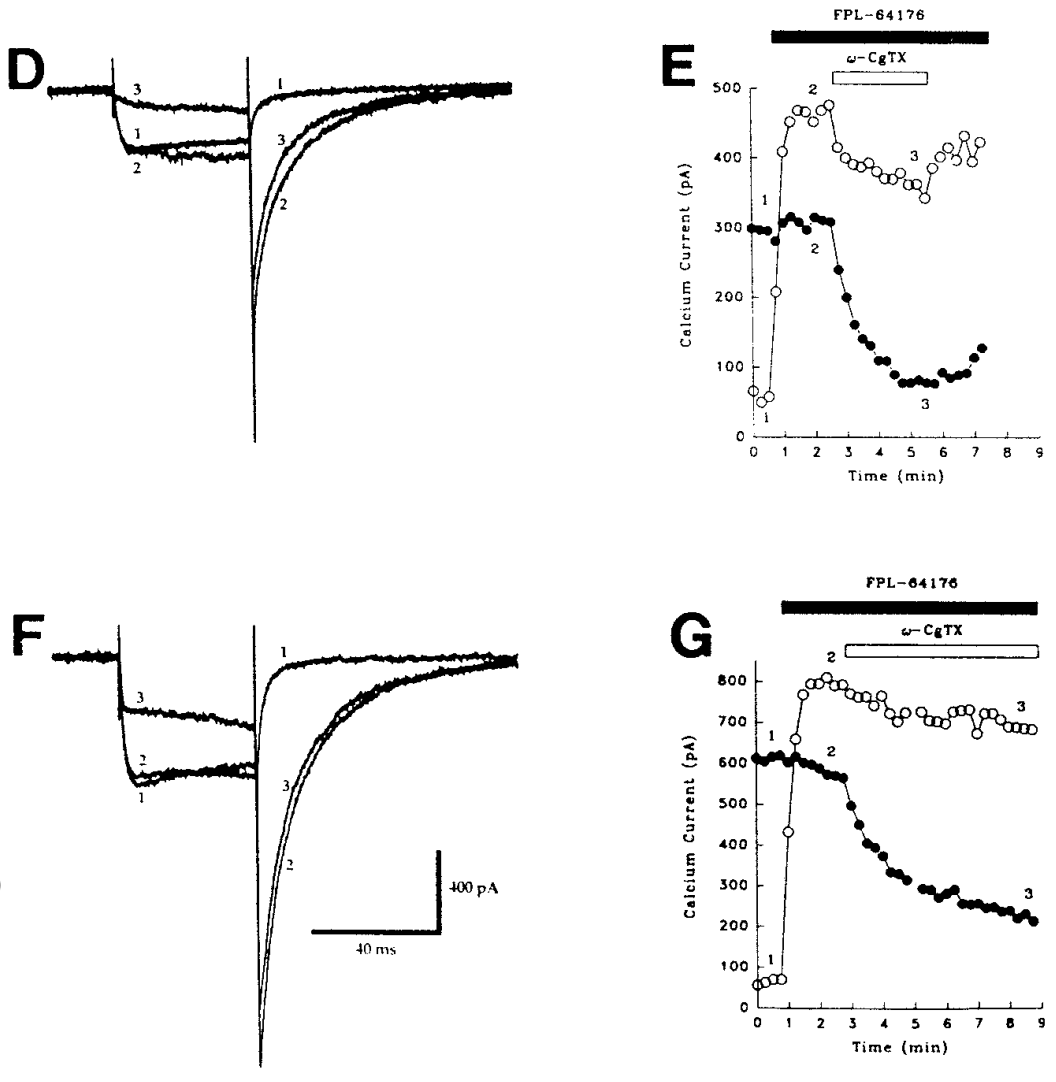

tials $(-20 \mathrm{mV})$ with current activated by test pulses that activate peak $\mathrm{Ca}^{2+}$ current $(+10 \mathrm{mV})$, we used a double-pulse protocol. The somatostatin effect in stage 34 neurons was within control ranges when tested with steps to $+10 \mathrm{mV}(52.3 \pm 2.4 \%)$, but when tested with steps to $-20 \mathrm{mV}$, the somatostatin effect effectively was eliminated $(4.1 \pm 4.4 \%, n=6$; see Fig. $8 A)$. The lack of effect of neuropeptides and modulators at depolarized potentials is commonly observed (Bean, 1989; Boland and Bean, 1993), but the apparent lack of effect at hyperpolarized potentials usually is not reported. When an apparent lack of neuromodulator effect at hyperpolarized potentials has been observed, it has been attributed to the predominance of calcium channel types at hyperpolarized potentials that are relatively insensitive to modulation (see Viana and Hille, 1996). To test this possibility, we activated calcium current in stage 34 neurons with the same double-pulse protocol described above, and we examined the pharmacologic sensitivity of current activated by test potentials to -20 and +10 $\mathrm{mV}$. $\omega$-CgTX GVIA blocked a large percentage of the current activated by steps to $+10 \mathrm{mV}(74.0 \pm 2 \% ; n=7$; Fig. $8 A$; see also Fig. 2) but had a much smaller effect on current activated by steps to $-20 \mathrm{mV}(21.0 \pm 4.4 \%$; Fig. $8 B)$. Nitrendipine blocked a large percentage of the current at both test potentials $(77.0 \pm 3.8$ at +10 $\mathrm{mV} ; 58.2 \pm 4.4$ at $-20 \mathrm{mV} ; n=3$; Fig. $8 C$ ). Thus, currents activated by relatively weak depolarizations (steps to $-20 \mathrm{mV}$ ) are carried predominately by L-type channels (see Kasai and Neher, 1992). The mixed pharmacologic and N-type currents activated with test potentials more positive than $-20 \mathrm{mV}$.

\section{DISCUSSION}

\section{Developmental changes in $\mathbf{C a}^{2+}$ current}

The development of $\mathrm{Ca}^{2+}$ channel types is critical for regulating the development and strength of synapses as well as synaptic 

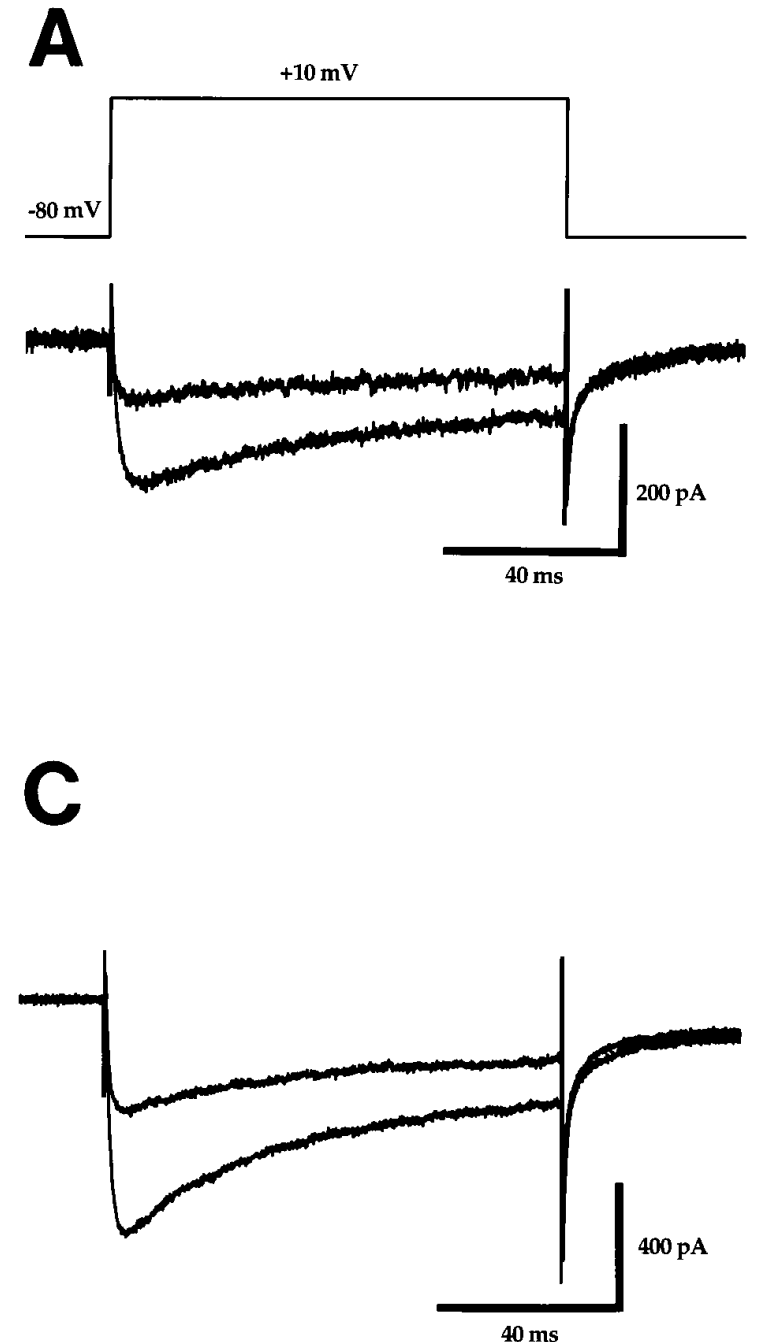

$40 \mathrm{~ms}$

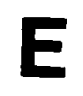

Figure 4. Somatostatin-mediated modulation of calcium current recorded via perforated patch-clamp techniques at stages $34(A, B), 37(C, D)$, and $40(E$, $F)$. $A, C, E$, Representative recordings of calcium current elicited by step depolarizations from $-80 \mathrm{mV}$ to $+10 \mathrm{mV}$. At all three developmental stages 100 nM somatostatin reduced calcium current by $\sim 50-60 \%$ without altering the kinetics of the current. $B, D, F$, Plots of the time course of somatostatinmediated modulation. The somatostatin modulation occurred with little or no desensitization over the time course measured and could be observed repeatedly on subsequent somatostatin (SOM) application.

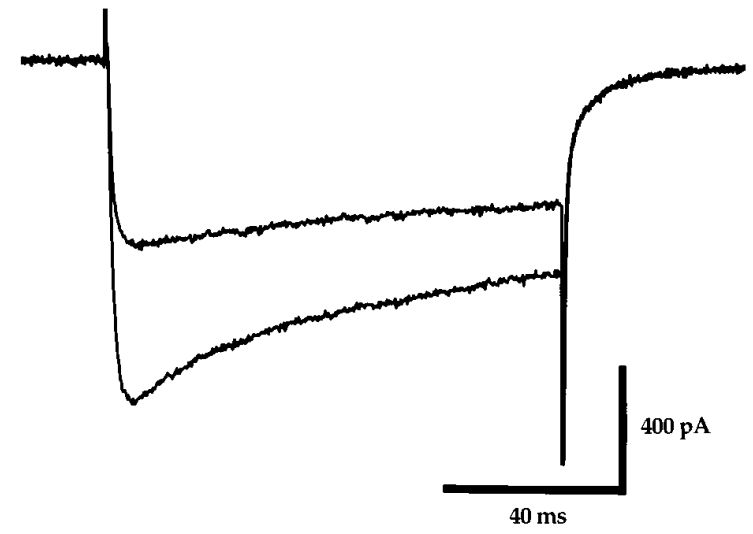

B

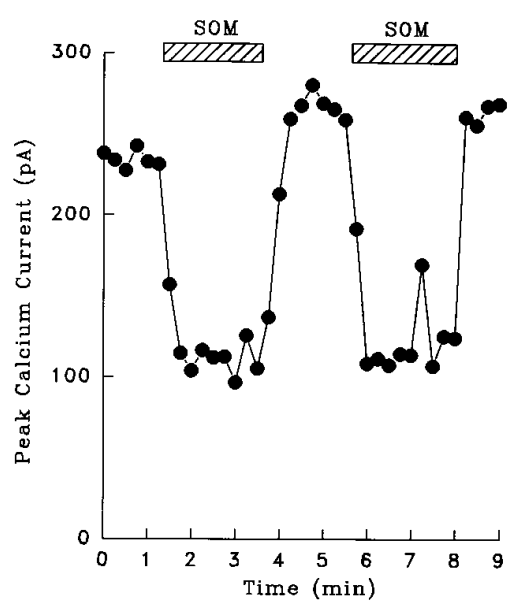

D

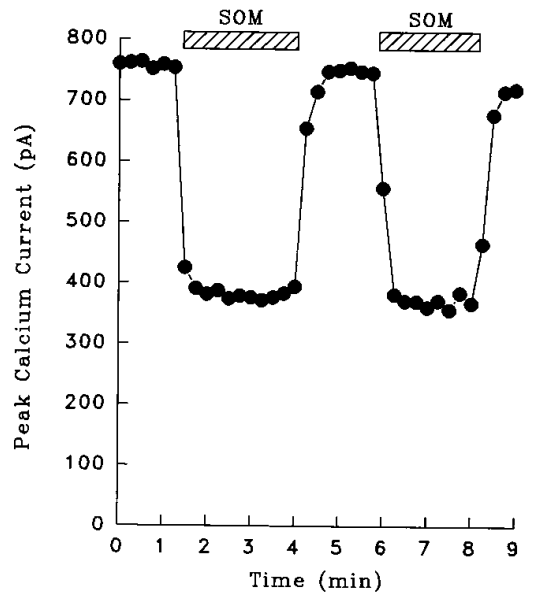

$\mathbf{F}$

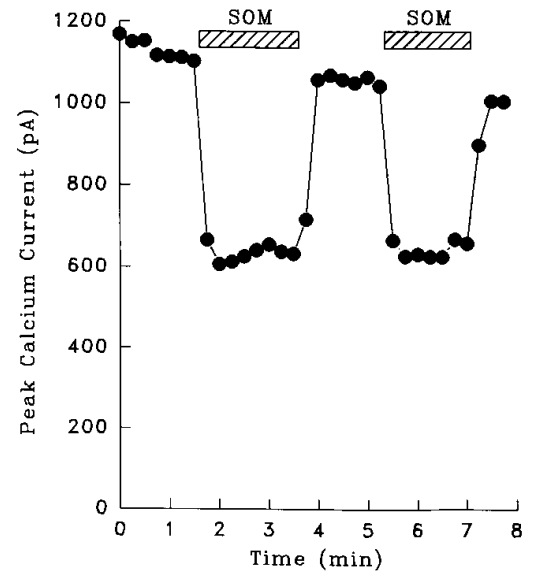



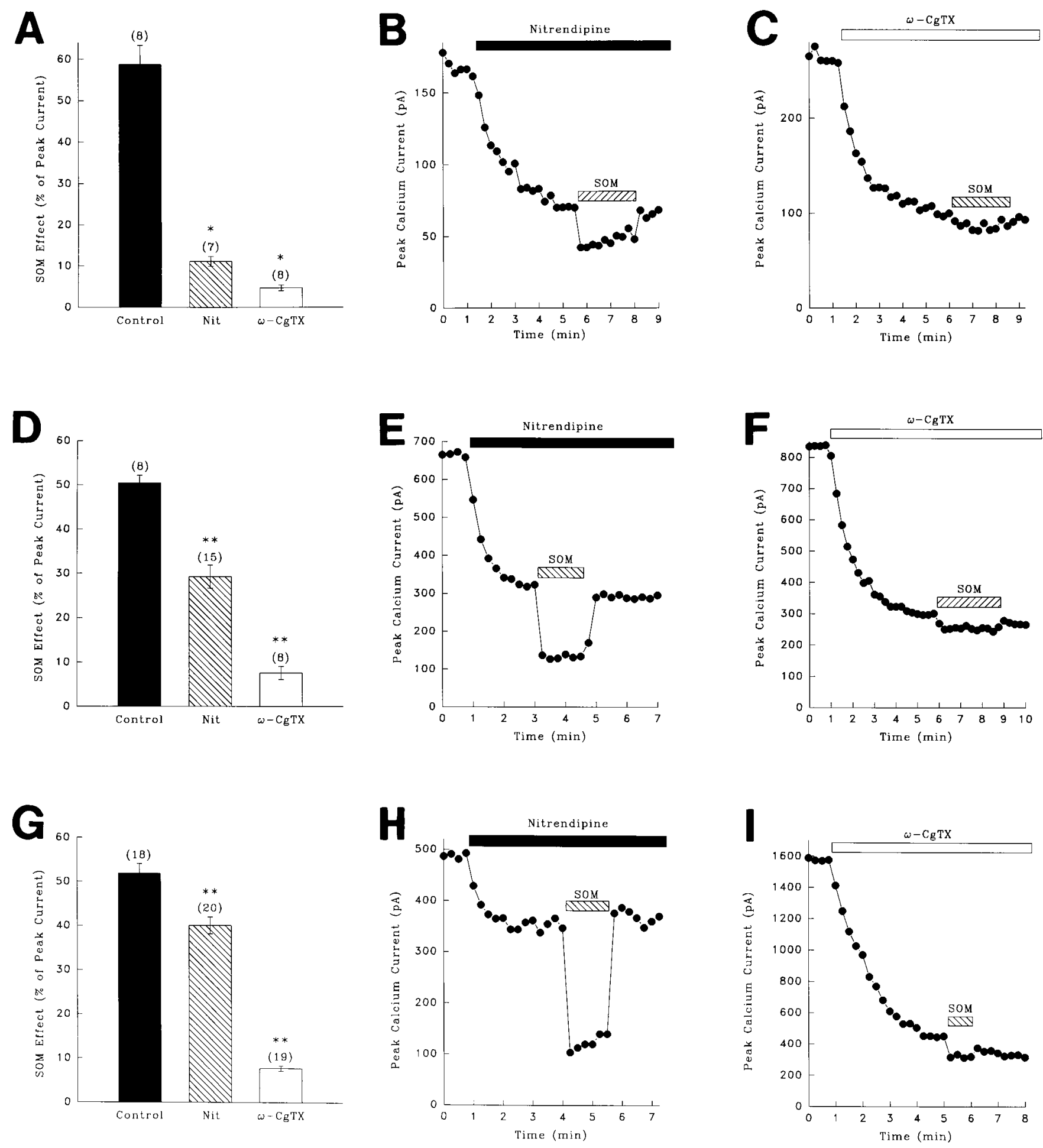

Figure 5. Pharmacologic sensitivity of somatostatin-mediated modulation of calcium current recorded via perforated patch-clamp techniques. At stage 34, somatostatin (SOM) modulation of calcium current was strongly occluded by pretreatment with either nitrendipine (Nit) or $\omega$-CgTX GVIA $(\omega$-CgTX) ( $A$; *significantly different from control, but not each other) as shown in representative time courses $(B, C)$. At stage $37, \omega$-CgTX was able to strongly occlude somatostatin modulation, but nitrendipine could occlude the effect of somatostatin only partially $(D ; * *$ significantly different from control and each other). Representative examples are shown in $E$ and $F$. At stage $40, \omega$-CgTX still was able to strongly occlude somatostatin modulation, but the effect of nitrendipine was very weak $(G)$, as demonstrated by representative time courses in $H$ and $I$ (**significantly different from control and each other). Nitrendipine $(20 \mu \mathrm{M})$ was used in the representative time courses shown in $B$ and $E$. Nitrendipine $(2 \mu \mathrm{M})$ was used in the representative time course shown in $H$. $\omega$-CgTX GVIA $(2 \mu \mathrm{M})$ was used in the representative time courses shown in $C, F$, and $I$. Numbers in parentheses represent the number of cells studied. Statistical analyses were performed with a one-way ANOVA with Tukey's post hoc test; significance was defined as $p<0.05$. 

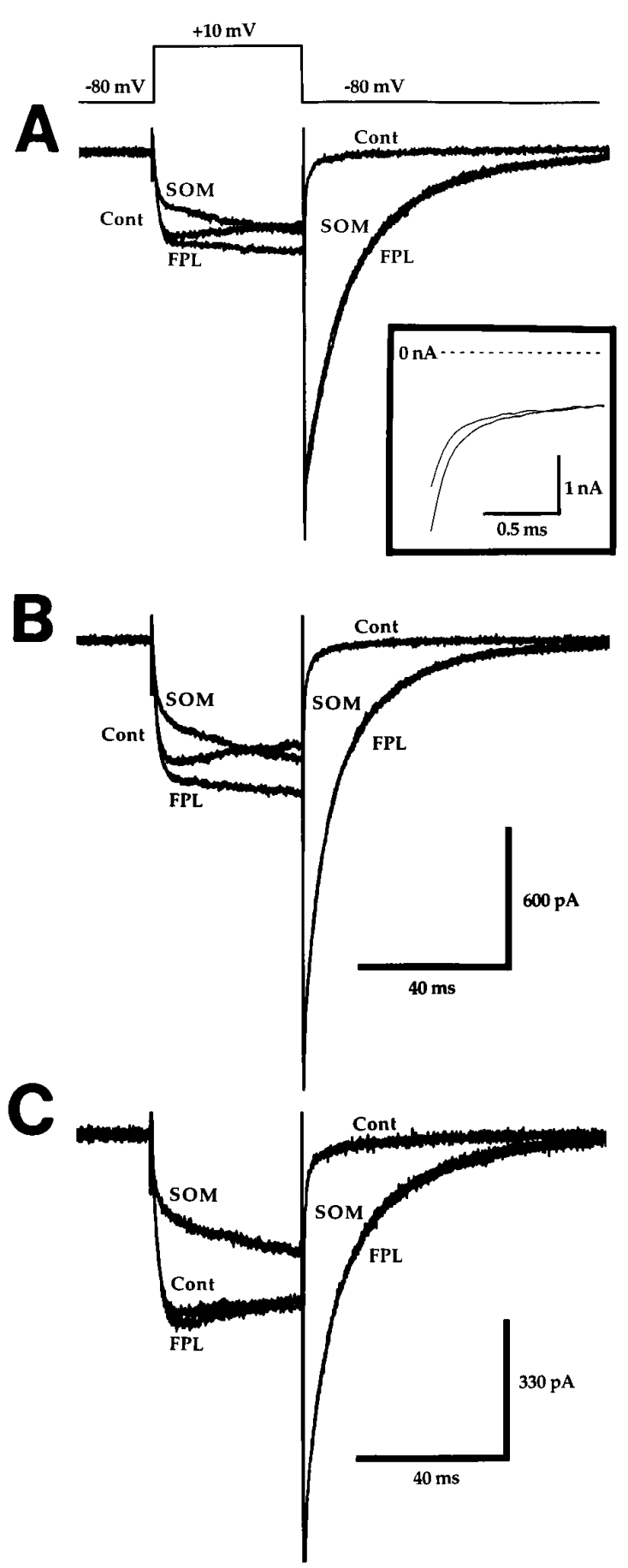

D

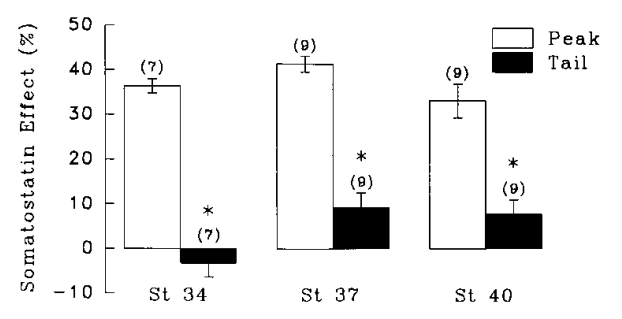

Figure 6. Somatostatin modulation of FPL 64176-elongated calcium currents recorded via traditional whole-cell recording techniques. Shown are representative examples of calcium current recorded before FPL 64176 application (Cont), after FPL 64176 application (FPL), and after somatostatin modulation of the FPL 64176-altered current (SOM) in

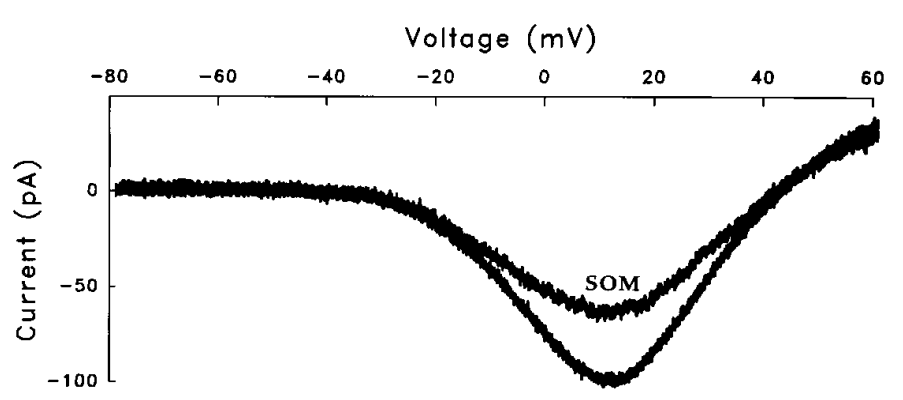

Figure 7. Representative somatostatin-mediated modulation of calcium current evoked by a $500 \mathrm{msec}$ voltage ramp from -80 to $+60 \mathrm{mV}$ in a stage 34 neuron. Somatostatin (SOM) modulation was absent at voltages below -15 and above $+35 \mathrm{mV}$.

plasticity and modulation. We have demonstrated a developmental change in $\mathrm{Ca}^{2+}$ current pharmacology in ciliary ganglia cell somata during the period of synapse formation between these neurons and intrinsic eye muscles. Our data suggest the presence of a $\mathrm{Ca}^{2+}$ channel type with the pharmacologic properties of both $\mathrm{N}$ - and L-type $\mathrm{Ca}^{2+}$ channels at early embryonic stages. However, by the end of the period of synapse formation with the periphery, the ciliary ganglion neurons express $\mathrm{Ca}^{2+}$ channels, the majority of which seem to fall into classically defined $\mathrm{N}$ - and L-type categories.

Previously, Gray et al. (1992) demonstrated that the dihydropyridine nifedipine blocked potassium-evoked ACh release from intact ciliary ganglion nerve terminals in the choroid coat at stage 40 , but not at post-hatch synapses, whereas $\omega$-CgTX GVIA inhibited ACh release much less effectively at stage 40 than at post-hatch synapses. Because Gray et al. (1992) were measuring the pharmacology of potassium-evoked ACh release, they could not determine whether two different channel types participated in the regulation of release at early stages or whether there was an embryonic channel with mixed pharmacology. Our data confirm the expression at early embryonic stages of a mixed pharmacologic channel in ciliary ganglion cell somata. The developmental period during which we measured a shift in $\mathrm{Ca}^{2+}$ current pharmacology is earlier than the shift in ACh release pharmacology described previously at periphery synapses (Gray et al., 1992). These differences in the developmental timing of the pharmacologic shift may be attributable to differences in the timing of ion channel expression changes between the soma and nerve terminal. However, differences in the methods of measuring this pharmacologic shift may make a direct comparison of these data difficult.

Developmental changes in $\mathrm{Ca}^{2+}$ current in neurons have been reported previously, but, in general, these reports have been limited either to changes in the magnitude of $\mathrm{Ca}^{2+}$ current expression during development (Dourado and Dryer, 1992; Desarmenien et

$\leftarrow$

stages $34(A), 37(B)$, and $40(C)$ neurons. Calibration bars in $B$ apply to $A$ also. Inset, Enlargement of a representative effect of somatostatin at stage 40 on the fast component of the FPL 64176-elongated tail current (similar effects on the fast component of the tail current were observed at all three developmental stages). This inset current record begins $100 \mu \mathrm{sec}$ after the cessation of the test pulse. $D$, Plot of the somatostatin effect on FPL 64176-altered peak (open bars) and FPL 64176-elongated tail (solid bars) currents at all three developmental stages (mean \pm SEM measured at $10 \mathrm{msec}$ after the cessation of the test pulse). Numbers in parentheses represent the number of cells studied. *Significantly different from effects on peak current; Student's $t$ test, $p<0.05$. 

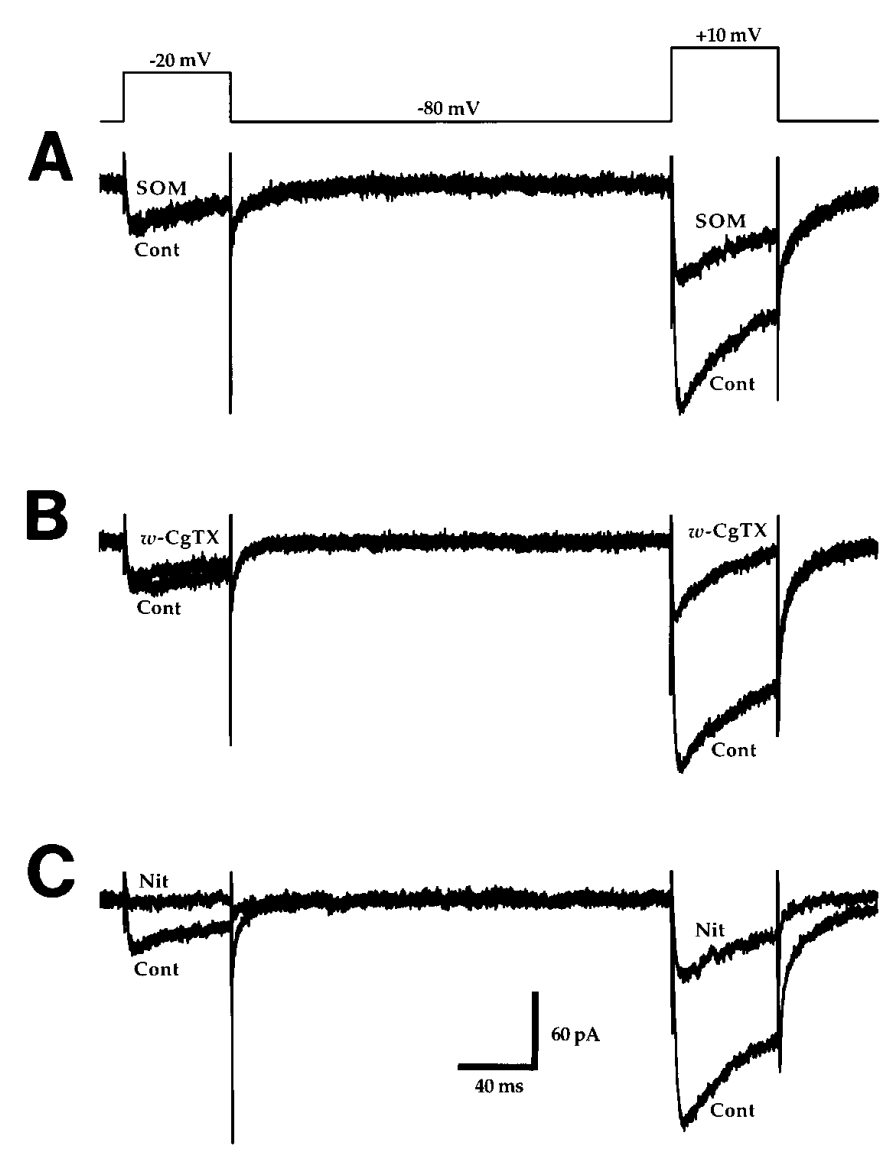

D

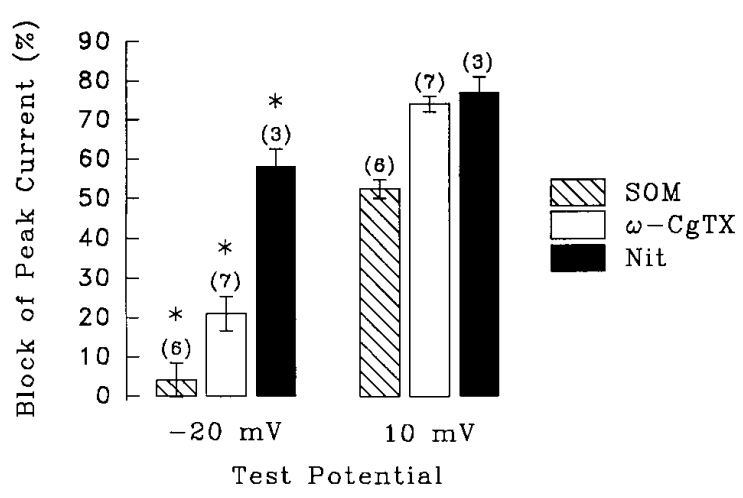

Figure 8. Measurement of pharmacologic sensitivity and somatostatin effects on calcium current in stage 34 neurons activated by test pulses to -20 and $+10 \mathrm{mV}$, recorded via perforated patch-clamp techniques. $A$, Somatostatin $(S O M)$ modulated calcium current activated by steps to +10 $\mathrm{mV}$ but was without effect on current activated by steps to $-20 \mathrm{mV}$. $B$, $\omega$-CgTX GVIA $(\omega$-CgTX;2 $\mu \mathrm{M})$ had a small effect on current activated by steps to $-20 \mathrm{mV}$ but had a strong effect on current activated by steps to $+10 \mathrm{mV}$. C, Nitrendipine $(\mathrm{Nit} ; 20 \mu \mathrm{M})$ had a strong effect on current activated at both -20 and $+10 \mathrm{mV}$. D, Plot of the effects of somatostatin $(S O M), \omega$-CgTX GVIA $(\omega-C g T X)$, and nitrendipine (Nit) tested with -20 and $+10 \mathrm{mV}$ test potentials (mean \pm SEM). Currents shown are an average of three sweeps. Numbers in parentheses represent the number of cells studied. *Significantly different from block of peak current measured at $+10 \mathrm{mV}$; Student's $t$ test, $p<0.05$.

al., 1993) or to changes in the relative expression of low-voltage and high-voltage-activated current types (Yaari et al., 1987; Gottman et al., 1988; Kostyuk, 1989; McCobb et al., 1989; Thompson and Wong, 1991; Gruol et al., 1992; Mynlieff and Beam, 1992; Rothe and Grantyn, 1994; Lorenzon and Foehring, 1995). In contrast, we report the expression in embryonic neurons of a mixed pharmacologic type of high-voltage-activated current that is replaced by high-voltage-activated current types that are blocked selectively by $\omega$-CgTX GVIA or dihydropyridine antagonists.

Transmitter release at some central synapses has been shown to be sensitive to multiple calcium channel antagonists (Luebke et al., 1993; Turner et al., 1993; Wheeler et al., 1994). These data often have been interpreted as evidence for the existence of multiple calcium channel types regulating release at central synapses, and this has been demonstrated in some cases (Wheeler et al., 1996). However, it is also possible that other synapses may express a calcium channel type that has pharmacologic sensitivity to several antagonists previously used as selective agents. Along these lines, Fisher and Bourque (1995) have identified a component of calcium current selectively expressed at rat supraoptic nerve terminals that is sensitive to both $\omega$-Aga IVA and $\omega$-CgTX GVIA. This novel pharmacology is not consistent with classical definitions of N-, P-, or Q-type calcium current and may represent a novel calcium channel type. Post-translational modifications and/or novel subunit combinations of pore-forming $\alpha-1$ subunits with one or more of the auxiliary calcium channel subunits $(\beta$, $\alpha_{2} \delta$, or $\gamma$ ) may result in a current with mixed pharmacologic sensitivity. Along these lines, N-type $\mathrm{Ca}^{2+}$ channels in rabbit brain have been shown to incorporate a subunit homologous to the $\beta$ subunit of L-type channels in skeletal muscle (Sakamoto and Campbell, 1991). The existence of an as yet uncharacterized splice variant for the $\alpha-1$ subunit is also possible. Our data might be explained by alterations in subunit translation and/or assembly as development proceeds. Alternatively, post-translational modifications at early embryonic stages may differ from those at later stages. Calcium current with sensitivity to both $\mathrm{N}$ - and L-type channel blockers has been reported in other preparations (Jones and Jacobs, 1990; Werth et al., 1991; Wang et al., 1992; Williams et al., 1992; Reeve et al., 1994), but these have not been examined from a developmental perspective. Until the expression of calcium channel subunit genes has been determined in developing chick ciliary ganglion neurons, the molecular relationship, if any, between channels with mixed pharmacologic sensitivity and those mediating other currents sensitive selectively to one pharmacologic agent will remain unknown.

Because the mixed pharmacologic channel type expressed at early embryonic stages does not activate at relatively hyperpolarized test potentials $(-20 \mathrm{mV})$ at which L-type channels are active (Figs. 7, 8), we suggest that the mixed pharmacologic type may be an "N-type" channel that is sensitive to dihydropyridines and FPL 64176 at early embryonic stages. Along these lines, it is interesting to note that the slowly decaying component of control tail currents (not elongated by FPL 64176) shown in Figure 8 is blocked only by nitrendipine (Fig. $8 C$ ). These tail currents recorded from stage 34 neurons are unaffected by somatostatin or $\omega$-CgTX GVIA (Fig. $8 A, B$ ), in contrast to FPL-elongated tail currents at this stage, which were blocked by $\omega$-CgTX GVIA (Fig. 3B). This comparison suggests that all current sensitive to $\omega$-CgTX GVIA at stage 34 (primarily the mixed pharmacologic type) normally deactivates much more quickly than the population of purely dihydropyridine-sensitive (L-type) currents present at this stage. Therefore, the mixed pharmacologic and N-type currents activated at similar test potentials and deactivated with similar time courses, and both were clearly distinct from L-type current activation and deactivation. Taken together, these data suggest that the mixed pharmacologic type current may be carried 
by an N-type channel with sensitivity to dihydropyridines and FPL 64176, instead of an L-type channel with sensitivity to $\omega$-CgTX GVIA. In any event, our data suggest a developmental regulation in chick ciliary ganglion neurons of those processes that result in the expression of calcium channels with mixed pharmacologic sensitivity.

\section{Developmental changes in somatostatin-mediated inhibition of $\mathrm{Ca}^{2+}$ current}

Throughout the changes in calcium current pharmacology described above, somatostatin consistently blocked $\sim 50-60 \%$ of peak $\mathrm{Ca}^{2+}$ current. Our data demonstrate that, at the beginning of the period of synapse formation with peripheral eye muscles (stage 34), the mixed pharmacologic channel type is the predominant type modulated by somatostatin. However, as development proceeds and the expression of the mixed pharmacologic channel is diminished, the proportion of nitrendipine-sensitive $\mathrm{Ca}^{2+}$ current modulated by somatostatin is reduced, whereas the proportion of $\omega$-CgTX GVIA-sensitive current modulated by somatostatin remains essentially unchanged. By stage 40 somatostatin targets predominantly the classically defined $\mathrm{N}$-type $\mathrm{Ca}^{2+}$ channel. In summary, despite changes in calcium current pharmacology, somatostatin-mediated modulation persists.

On the basis of the data showing a significant occlusion of the somatostatin effect on peak $\mathrm{Ca}^{2+}$ current by nitrendipine and the effects of $\omega$-CgTX GVIA on FPL 64176-elongated tail currents, especially at stage 34 , one would have expected somatostatin to modulate FPL 64176-elongated tail currents at early embryonic stages. However, we were unable to demonstrate an effect of somatostatin on FPL 64176-elongated tail currents at stage 34 . There are at least two possible explanations for these data. There may be two subpopulations of mixed pharmacologic channels, only one of which is sensitive to FPL 64176. If this were the case, one would have to postulate that both subpopulations are sensitive to dihydropyridines and $\omega$-CgTX GVIA and that somatostatin only modulates the subpopulation that is insensitive to FPL 64176. We consider this unlikely, because somatostatin did not affect dihydropyridine-elongated (Bay K 8644) tail currents either. Alternatively, it is possible that FPL 64176 alters calcium channels such that interactions with G-proteins are affected (see Scott and Dolphin, 1987; Dolphin and Scott, 1988, 1989). Because the $\beta$ subunit of calcium channels has been hypothesized to interact with the $\alpha-1$ subunit in such a way as to affect both G-protein interactions (Campbell et al., 1995) and dihydropyridine binding (Lacerda et al., 1991; Varadi et al., 1991; Mitterdorfer et al., 1994), the binding sites for G-proteins and dihydropyridines may be close enough to each other that the two ligands interact. If FPL 64176 binds to the calcium channel in a similar location, it may affect G-protein interactions. Along these lines, the effects of somatostatin on FPL 64176-enhanced peak current were smaller than observed with control currents (compare solid bars in Fig. 5A,D, $G$ with open bars in Fig. $6 D$ ); however, it is difficult to make a direct comparison, given the effects of FPL 64176 on peak current kinetics and amplitude.

In summary, during the early period of synapse formation with target muscle, ciliary ganglion neurons express a small percentage of classically defined $\mathrm{N}$ - and L-type calcium current and a large percentage of calcium current with mixed pharmacologic sensitivity to $\omega$-CgTX GVIA, nitrendipine, and FPL 64176. This mixed sensitivity is eliminated as these neurons mature, such that by the end of the period of synapse formation $\sim 75 \%$ of the current can be defined as N-type (irreversibly inhibited by
$\omega$-CgTX GVIA), and 25\% can be defined as L-type (selectively sensitive to dihydropyridines). Despite this change in calcium current pharmacology, sensitivity to somatostatin persists throughout this phase of embryonic development.

\section{REFERENCES}

Bean BP (1989) Neurotransmitter inhibition of neuronal calcium currents by changes in channel voltage dependence. Nature 340:153-155.

Boland L, Bean BP (1993) Modulation of N-type calcium channels in bullfrog sympathetic neurons by luteinizing hormone-releasing hormone: kinetics and voltage dependence. J Neurosci 13:516-533.

Campbell V, Berrow NS, Fitzgerald EM, Brickley K, Dolphin AC (1995) Inhibition of the interaction of G-protein Go with calcium channels by the calcium channel beta-subunit in rat neurones. J Physiol (Lond) 485:365-372.

Coulombe JN, Nishi R (1991) Stimulation of somatostatin expression in developing ciliary ganglion neurons by cells of the choroid layer. J Neurosci 11:553-562.

Desarmenien MG, Clendening B, Spitzer NC (1993) In vivo development of voltage-dependent ionic currents in embryonic Xenopus spinal neurons. J Neurosci 13:2575-2581.

De Stefano ME, Ciofi Luzzatto A, Mugnaini E (1993) Neuronal ultrastructure and somatostatin immunolocalization in the ciliary ganglion of chicken and quail. J Neurocytol 22:868-892.

Dolphin AC, Scott RH (1988) Actions of $\mathrm{Ca}^{2+}$ channel ligands depend on G-proteins. $\mathrm{Ca}^{2+}$ agonists/antagonists and GTP. Trends Pharmacol Sci 9:394-395.

Dolphin AC, Scott RH (1989) Interaction between calcium channel ligands and guanine nucleotides in cultured rat sensory and sympathetic neurons. J Physiol (Lond) 413:271-288.

Dourado MM, Dryer SE (1992) Changes in the electrical properties of chick ciliary ganglion neurons during embryonic development. J Physiol (Lond) 449:411-428.

Dryer SE (1994) Functional development of the parasympathetic neurons of the avian ciliary ganglion: a classic model system for the study of neuronal differentiation and development. Prog Neurobiol 43:281-322.

Dryer SE, Dourado MM, Wisgirda ME (1991) Properties of $\mathrm{Ca}^{2+}$ currents in acutely dissociated neurons of the chick ciliary ganglion: inhibition by somatostatin-14 and somatostatin-28. Neuroscience 44:663-672.

Epstein ML, Davis JP, Gellman LE, Lamb JR, Dahl JL (1988) Cholinergic neurons of the chicken ciliary ganglion contain somatostatin. Neuroscience 25:1053-1060.

Fisher TE, Bourque CW (1995) Distinct $\omega$-agatoxin-sensitive calcium currents in somata and axon terminals of rat supraoptic neurons. J Physiol (Lond) 489:383-388.

Gottman K, Dietzel ID, Kux HD, Huck S, Rohrer H (1988) Development of inward currents in chick sensory and autonomic neuronal precursor cells in culture. J Neurosci 8:3722-3732.

Gray DB, Pilar GR, Ford MJ (1989) Opiate and peptide inhibition of transmitter release in parasympathetic nerve terminals. J Neurosci 9:1683-1692.

Gray DB, Zelazny D, Manthay N, Pilar G (1990) Endogenous modulation of ACh release by somatostatin and the differential roles of $\mathrm{Ca}^{2+}$ channels. J Neurosci 10:2687-2698.

Gray DB, Brusés JL, Pilar GR (1992) Developmental switch in the pharmacology of $\mathrm{Ca}^{2+}$ channels coupled to acetylcholine release. Neuron 8:715-724.

Gruol DL, Deal CR, Yool AJ (1992) Developmental changes in calcium conductances contribute to the physiological maturation of cerebellar Purkinje neurons in culture. J Neurosci 12:2838-2848.

Hamburger V, Hamilton HL (1951) A series of normal stages in the development of the chick embryo. J Morphol 88:49-92.

Hille B (1994) Modulation of ion channels by G-protein-coupled receptors. Trends Neurosci 17:531-535.

Horn R, Marty A (1988) Muscarinic activation of ionic currents measured by a new whole-cell recording method. J Gen Physiol 92:145-159.

Jones SW, Jacobs LS (1990) Dihydropyridine actions on calcium currents of frog sympathetic neurons. J Neurosci 10:2261-2267.

Kasai H, Neher E (1992) Dihydropyridine-sensitive and $\omega$-conotoxinsensitive calcium channels in a mammalian neuroblastoma-glioma cell line. J Physiol (Lond) 448:161-188.

Kostyuk PG (1989) Diversity of ion channels in cellular membranes. Neuroscience 28:253-261. 
Kunze DL, Rampe D (1992) Characterization of the effects of a new $\mathrm{Ca}^{2+}$ channel activator, FPL 64176, in GH3 cells. Mol Pharmacol 42:666-670.

Lacerda AE, Haeyoung SK, Ruth P, Perez-Reyes E, Flockerz V, Hofmann F, Birnbaumer L, Brown AM (1991) Normalization of current kinetics by interaction between the alpha1 and beta subunits of the skeletal muscle dihydropyridine-sensitive $\mathrm{Ca}^{2+}$ channel. Nature 352:527-530.

Lorenzon NM, Foehring RC (1995) Characterization of pharmacologically identified voltage-gated calcium channel currents in acutely isolated rat neocortical neurons. II. Postnatal development. J Neurophysiol 73:1443-1451.

Luebke JI, Dunlap K, Turner TJ (1993) Multiple calcium channel types control glutamatergic synaptic transmission in the hippocampus. Neuron 11:895-902.

McCobb DP, Best PM, Beam KG (1989) Development alters the expression of calcium currents in chick limb motoneurons. Neuron 2:1633-1643.

McKechnie R, Killingback P, Naya I, O'Connor S, Smith G, Wattam D, Wells E, Whitehead Y, Williams G (1989) Calcium channel activator properties in a novel non-dihydropyridine, FPL 64176. Br J Pharmacol 98:673P.

Meriney SD, Gray DB, Pilar GR (1994) Somatostatin-induced inhibition of neuronal $\mathrm{Ca}^{2+}$ current modulated by cGMP-dependent protein kinase. Nature 369:336-339.

Mitterdorfer J, Froschmayr M, Grabner M, Striessnig J, Glossmann H (1994) Calcium channels: the beta-subunit increases the affinity of dihydropyridine and $\mathrm{Ca}^{2+}$ binding sites of the alpha1-subunit. FEBS Lett 352:141-145.

Mynlieff M, Beam KG (1992) Developmental expression of voltagedependent calcium currents in identified mouse motoneurons. Dev Bio 152:407-410.

O’Dowd DK, Ribera AB, Spitzer NC (1988) Development of voltagedependent calcium, sodium, and potassium currents in Xenopus spinal neurons. J Neurosci 8:792-805.

Rae J, Cooper K, Gates P, Watsky M (1991) Low access resistance perforated patch recordings using amphotericin B. J Neurosci Methods 37:15-26.

Rampe D, Anderson B, Rapien-Pryor V, Li T, Dage RC (1993) Comparison of the in vitro and in vivo cardiovascular effects of two structurally distinct $\mathrm{Ca}^{2+}$ channel activators, BAY K 8644 and FPL 64176 J Pharmacol Exp Ther 265:1125-1130.

Randall A, Tsien RW (1995) Pharmacological dissection of multiple types of $\mathrm{Ca}^{2+}$ channel currents in rat cerebellar granule neurons J Neurosci 15:2995-3012.

Reeve HL, Vaughan PFT, Peers C (1994) Calcium channel currents in undifferentiated human neuroblastoma (SH-SY5Y) cells: actions and possible interactions of dihydropyridines and $\omega$-conotoxin. Eur J Neurosci 6:943-952.
Rothe T, Grantyn R (1994) Retinal ganglion neurons express a toxinresistant developmentally regulated novel type of high-voltageactivated calcium channel. J Neurophysiol 72:2542-2546.

Sakamoto J, Campbell KP (1991) A monoclonal antibody to the beta subunit of the skeletal muscle dihydropyridine receptor immunoprecipitates the brain $\omega$-conotoxin GVIA receptor. J Biol Chem 266:18914-18919.

Scholz KP, Miller RJ (1995) Developmental changes in presynaptic calcium channels coupled to glutamate release in cultured rat hippocampal neurons. J Neurosci 15:4612-4617.

Scott RH, Dolphin AC (1987) Activation of a G-protein promotes agonist responses to calcium channel ligands. Nature 330:760-762.

Spitzer NC (1994) Development of voltage-dependent and ligand-gated channels in excitable membranes. Prog Brain Res 102:169-179.

Thompson SM, Wong RKS (1991) Development of calcium current subtypes in isolated rat hippocampal pyramidal cells. J Physiol (Lond) 439:671-689.

Turner TJ, Adams ME, Dunlap K (1993) Multiple $\mathrm{Ca}^{2+}$ channel types coexist to regulate synaptosomal neurotransmitter release. Proc Natl Acad Sci USA 90:9518-9522.

Varadi G, Lory P, Schultz D, Varadi M, Schwartz A (1991) Acceleration of activation and inactivation by the beta subunit of the skeletal muscle calcium channel. Nature 352:159-162.

Viana F, Hille B (1996) Modulation of high-voltage-activated calcium channels by somatostatin in acutely isolated rat amygdaloid neurons. J Neurosci 16:6000-6011.

Wang X, Treistman SN, Lemos JR (1992) Two types of high-threshold calcium currents inhibited by $\omega$-conotoxin in nerve terminals of rat neurohypophysis. J Physiol (Lond) 445:181-199.

Werth JL, Hirning LD, Thayer SA (1991) $\omega$-Conotoxin exerts functionally distinct low and high affinity effects in the neuronal cell line NG108-15. Mol Pharmacol 40:742-749.

Wheeler DB, Randall A, Tsien RW (1994) Roles of N-type and Q-type $\mathrm{Ca}^{2+}$ channels in supporting hippocampal synaptic transmission. Science 264:107-111.

Wheeler DB, Randall A, Tsien RW (1996) Changes in action potential duration alter reliance of excitatory synaptic transmission on multiple types of $\mathrm{Ca}^{2+}$ channels in rat hippocampus. J Neurosci 16:2226-2237.

Williams ME, Feldman DH, McCue AF, Brenner R, Velicelebi G, Ellis SB, Harpold MM (1992) Structure and functional expression of alpha1, alpha2, and beta subunits of a novel human neuronal $\mathrm{Ca}^{2+}$ channel subtype. Neuron 8:71-84.

Yaari Y, Hamon B, Lux HD (1987) Development of two types of calcium channels in cultured mammalian hippocampal neurons. Science 235:680-682.

Yawo H, Momiyama A (1993) Re-evaluation of calcium currents in preand postsynaptic neurons of the chick ciliary ganglion. J Physiol (Lond) 460:153-172. 